\title{
An Economic Analysis of New Zealand's Conservation Strategies
}

\author{
John L. Craig
}

A recent publication from the New Zealand Business Roundtable titled Conservation Strategies for New Zealand, and written for the Tasman Institute by Peter Hartley, an Australian-born economist at Rice University, Texas, briefly produced ripples of unease through New Zealand conservation circles. It was publicly dismissed by most conservation groups and Department of Conservation (DoC). Even Dr Nick Smith, the Minister of Conservation, condemned the report in the very week that his foreword to the government department's annual report noted that the conservation agenda included 'encouraging public participation in conservation' (DoC, 1997a).

Despite its importance, the debate about the publication appears to have stopped. No one has challenged the assertion by DoC senior managers 'that while economics has much to offer conservation ... this report ... has nothing positive to contribute' (DoC, 1997b). Is this the case? An analysis of conservation in New Zealand, of the contents of the book and of the reaction to it demonstrates the difficulties and conflicts that hinder effective conservation.

\section{Conservation in New Zealand}

Like many other parts of the world, New Zealand is continuing to lose biodiversity (MfE, 1997), has no biodiversity or sustainability strategy and little knowledge of natural capital, and lacks the accountability measures to ensure that it could achieve these goals if it had them. As with all island nations, biodiversity loss and degradation in New Zealand are more rapid than on larger land masses, and so require prompt and flexible management responses. Superficially, the New Zealand government can claim to have shown leadership on a range of issues; one of the most striking is the reservation (protection) of more than 30 per cent of the country's land area for conservation. But most agencies and the general public fail to appreciate that this measure is 'greenwash', in that it ignores the continuing decline in biodiversity across more than 95 per cent of this public conservation estate.

DoC is a government agency charged under the Conservation Act 1987 with 'the preservation and protection of natural and historic resources for the purposes of maintaining their intrinsic values, providing for their appreciation and recrea-

John Craig is Professor of Environmental Management at The University of Auckland. 
tional enjoyment by the public and safeguarding the options of future generations'. Since its formation in 1987 , its budget has been gradually declining, though it has been recently supplemented for tagged projects such as possum control and visitor safety. Its many deficiencies are usually attributed to inadequate funding. Regular calls by conservation non-governments organisations (NGOs) for additional government finance have been largely ineffective.

Since the fiscal crises of the 1980s, New Zealand has undertaken reforms that aim to reduce the role of government and increase the responsibilities of communities, agencies and private individuals. Conservation remains one of the few areas where no split has been introduced between the funders of government services and the agencies that supply them.

DoC was formed by an amalgamation of staff from sections of previous government departments including those responsible for national parks and reserves (Lands \& Survey), native protection and former production forests (Forest Service) and large animal biodiversity (Wildlife Service). Each group brought a pre-existing mentality into the new organisation, whose overall approach was to separate the protection aspects of the old departments from the exploitative aspects (land development, extraction forestry and game control). The new department resolved the uneasy alliance of resource extraction and destruction with protection, but enjoyed only a limited capacity to raise money. The established mindset viewed people as the problem rather than the solution, and certainly not as customers. A strong culture emerged of lock-up protection with command and control management.

DoC has often examined its performance and attempted to redefine and enhance its role. For example, in 1992 it began to ask staff and associates what they wanted and what they thought was wrong. Maori wanted an active or sustainable approach to conservation rather than a passive lock-up approach. Associates (NGOs, councils, and government departments) had a 'poor' image of DoC, seeing it as 'overprotective ... driven by the certainty that it was always right ... bureaucratic, impractical and out of touch with reality' (DoC, 1992:7). Neighbours of the public conservation estate observed that DoC advocated 'protection' on private land while neglecting nearby parts of the conservation estate. The DoC management team argued that 'efficiency and accountability are essential but these are not always appropriate as core criteria' (DoC, 1992:5). The result was a restructuring (one of many) aimed at enhancing DoC's focus on protection of biodiversity and ecosystem processes along with a commitment to share responsibilities with a wide range of organisations, groups and individuals. Yet this apparently bold and self-searching initiative appears to have resulted in little change.

Early in 1994, Anne Stewart and I pointed out that DoC's annual reports appeared to dwell on actions rather than outcomes, which made it difficult to calculate conservation benefits. We argued that conservation benefited from a business approach and that emphasising the legislative requirement of actions for 'intrinsic values and for future generations' minimised accountability since the chosen customers had no voice (Craig \& Stewart, 1994:165). We also stressed that current actions were not even maintaining existence values, since protection was implemented 
largely through benign neglect. Our views were strongly influenced by a nationwide public survey that was published subsequently (Craig et al., 1995).

The eradication of kiore in 1993 from Tiritiri Matangi Island brought me into direct contact with the coercive aspects of DoC's conservation management, a factor consistently raised by Maori (see Taiepa et al., 1997). The island had been restored through replanting and reintroduction of rare fauna by massive community efforts initiated long before the establishment of DoC. Even though several Maori communities had requested a moratorium on kiore eradications (Roberts, 1995), DoC urged Supporters of Tiritiri to provide finance for an aerial drop of poison. When confronted in a meeting with the request that tunnels be used rather than an aerial drop in order to reduce incidental kills of rare birds and to allow long-term research programmes to continue, the DoC officials argued for net conservation benefit. For them, short-term kills of some highly threatened and some common species would not threaten long-term viability and would provide major conservation benefits. They dismissed as irrelevant research programmes on the island, which is classified as a scientific reserve. After threatening to 'close the island to the public' and 'to prevent all future translocations of animals' if resistance continued, the DoC officials got their way. Kiore were eradicated, the predicted loss of birds occurred (including the near-eradication of one species), and tens of thousands of dollars invested in independently financed conservation science were wasted. While the long-term result will be beneficial, the short-term result was unnecessarily destructive.

The 1995 tragedy at Cave Creek, where the collapse of a DoC-made viewing platform killed 14 people, profoundly influenced the approach of DoC, which immediately became preoccupied with responsibility and customer safety. The costs of this change of priorities further stretched a declining budget. Hampered by a parliament directive that free access meant free use, DoC was unable to recoup the additional costs of structure safety. Against the general trend towards user charges and closer targeting of welfare, taxpayers are in effect subsidising international tourists and local users predominantly from higher income brackets.

In 1997 New Zealand's first comprehensive report on the state of the environment appeared (MfE, 1997). It highlights the appalling state of the country's biodiversity and the continuing decline in both 'protected and unprotected' areas. Introduced herbivores, especially possum, goats and deer, are destroying the structure of forests and other ecosystems; while introduced predatory mammals, especially mustelids, ship rats and feral cats, are destroying much of the wildlife. In its recently published five-year plan, DoC (1998) reports that it has programmes in place to control sustainably possum and goats on approximately 15 per cent of the public conservation estate, which it hopes to increase to 25 per cent by 2000 . The remaining area of more than $5 \mathrm{~m}$ hectares of at-risk ecosystems is left to decline further, while virtually the whole estate is without protection from mammalian predators. These predators are wiping out birds and insects that are the main pollinators and seed dispersers, thus threatening New Zealand's forests and New Zealanders' ability 
to experience functioning native ecosystems with most native species in more than relic densities.

Like much of the world until the late 1980s, New Zealand's approach to evaluating conservation relative to other activities relied on special value judgments rather than a mix of values, including economic ones. Consequently, the debate is predominantly political (three major conservation NGOs maintain head offices in Wellington, the political capital). The inevitable result, as Costanza et al. (1997:253) stress, is that because ecosystem goods and services are not fully captured in quantified terms comparable to economic services and manufactured capital, they are often given too little weight in policy decisions. This neglect may ultimately compromise the sustainability of humans in the biosphere'.

\section{Peter Hartley's Contribution}

Peter Hartley's book provides the first economic analysis of conservation strategies in New Zealand. As such, it could be seen as an extremely valuable aid to the Minister's objective of 'advancing the view that conservation is an investment' (DoC, 1997a:5). But it is important to realise at the outset that the book is not a complete or even a balanced analysis. The research was undertaken without any official cooperation from DoC. Hartley responds to the defensive reaction by DoC officials to his project by observing that ' $\mathrm{DoC}$ is a public organisation, not a secret one ... therefore, DoC has to be accountable to the people of New Zealand for its actions' (1997:27). The greatest strength of the book is its remarkable breadth. It clearly establishes many of the dimensions of the much-needed debate on conservation in New Zealand.

Hartley bases his evaluation on a selection of published documents from DoC (although he failed to reference many important policy documents such as the Conservation Management Strategies), and personal discussions and impressions received while travelling throughout the country visiting both the public conservation estate and the few private conservation enterprises. He examines the issues of legislation, structure and efficiency of government conservation; the possible role of greater non-government participation in conservation, including the role of markets (the ability of customers to dictate priorities through a willingness to pay directly); and ways to enhance conservation objectives on private land. He also examines Maori development and issues of historic heritage management. He only superficially addresses the multitude of externalities that allow parts of the business sector (especially farming, fishing and forestry) to avoid conservation (and sustainability) activities.

History and context. Chapter 1 covers the state of the New Zealand environment and the history of the public conservation estate and government reforms that led to the formation of DoC. Hartley then provides an overview of environmental management structures and the functions of DoC, public perceptions of DoC, and the importance of the Treaty of Waitangi. He comments on the overwhelmingly negative reception he received as a representative of business from most individuals and 
groups associated with conservation. (Nowhere does he consider the current difficult relationship between the conservation movement and business in New Zealand.)

Resource allocation. Chapter 2 deals with markets, politics and voluntary activity. It sets out the broad dimensions of the current debate of government reform. Conservation, like many environmental issues, involves publicly owned resources the costs of use and abuse of which are hidden under the guise of being everyone's birthright. Contrasting the fate of moa and fishing with that of owned agricultural stock, Hartley points to the advantages of property rights in which privileges and responsibilities are clearly defined. He also contrasts market power (where individuals can pay for resources or services) with political power (where politically acceptable groups influence but where governments decide and provide, as is current in conservation). Some markets are inefficient because controlling access is difficult and free riding is possible; air and water pollution are salient examples of such inefficiency. The current lack of markets precludes informed discussion.

Hartley notes the considerable contribution of voluntary activity in conservation, even though it is sometimes subjected to bureaucratic obstruction. He concludes that community management of initiatives such as Tiritiri Island can enhance conservation outcomes at less cost to government. The lack of references to the considerable effort that some DoC staff are putting into fostering voluntary conservation in New Zealand probably stems from communication barriers erected by DoC senior management.

Competing uses for natural resources. Chapter 3 analyses the difficult wording of conservation legislation. The idea of 'intrinsic value' is problematic and selfcontradictory; the law needs to be reworded so as to refer to a measurable value (examples of which are suggested). Quotations from DoC and non-DoC writers on conservation management reveal the contrast between the former's internally focused criteria and the latter's clearly articulated and customer-focused objectives that allow effective targeting of conservation resources. Removing references to 'intrinsic value' from the Conservation Act and placing the DoC-administered public conservation estate under the strictures of the Resource Management Act would greatly enhance conservation. This signals the importance of the philosophical debate about whether conservation is better promoted through protection (as under the Conservation Act) or through sustainable use (as under the Resource Management Act).

The inefficiency of political decision-making in conservation is illustrated with the example of Kaimanawa horses and contrasted with the example of efficient private high-country conservation where sheep threaten tussock ecosystems. In both situations, control of a grazer enhanced survival of native plant communities but politics dominated where a government agency was involved. Additional topics include maintaining conservation values through multiple use, integration of conservation with other economic goals, minimising cost by using local knowledge 
(especially of Maori), and ensuring continuing management rather than lock-up neglect.

Achieving conservation goals. Hartley argues in Chapter 4 that all resource allocation decisions should take into account not only relevant environmental costs and benefits but also the costs and benefits of alternative uses of conservation land. Conservation of natural resources, to be achieved, needs to be integrated into economic decision-making. Given that there is no asset valuation of the public conservation estate that includes biodiversity, use, heritage and economic values used by groups such as Parks Victoria, Auckland Regional Council and New Plymouth District Council, Hartley's demand for accountable resource allocations among reserves is timely. No private organisation could survive with such a limited understanding of its assets or monitoring systems.

Hartley observes that DoC gives the protection of intrinsic values a higher priority than customer satisfaction. Since no objectives are declared and no cost-benefit analyses are undertaken, coherent policy-making is impossible. Hartley argues for consideration of net conservation benefit rather than simplistic justifications based on absolute rules determined by the values of government officials. The use of concessions and contract services suggests a largely ad hoc approach that focuses more on minimising risk or 'maximising revenue' (DoC, 1998:56) than on maximising conservation benefit. The estimated NZ $\$ 44 \mathrm{~m}$ spent annually on subsidising visitor services should be reduced.

Hartley questions DoC's ready acceptance of parliament's insistence that legislation requiring free access to areas managed by DoC means that they must be free to users. There is considerable debate on efficient allocation of visitor facilities and the value of obtaining customer profiles at the time of paying, a common practice in US parks. The currently inadequate information on customers and their needs is a likely cause of untargeted and often inefficient and inappropriate service provision. Hartley argues for charging users of the public conservation estate and for large fines for trespass, but suggests ways of charging New Zealand taxpayers and regular users less than tourists.

Hartley acknowledges that some people appreciate nature indirectly (that is, without ever visiting it), and that this justifies some public subsidy; but it does not justify monopolistic public supply of conservation value or providing it free to direct consumers of it.

The book refers to some examples of the greater conservation benefits that flow from ownership of, and strictly controlled markets in, wildlife than from trade bans that lead to black markets. However, it does not broach the logically related issue of customary harvest by Maori and the farming of native rather than introduced species: a seemingly contentious topic that requires wider debate. It similarly does not mention that $\mathrm{DoC}$ issue permits for killing animals that others would pay to keep in captivity if DoC allowed them to. 
Private conservation. Chapter 5 covers the benefits of private as opposed to government provision of conservation, and outlines three successful examples of privately run ecotourism ventures with conservation benefits (Ngai Tahu Whalewatching, Yellow-eyed Penguin Trust, and Wainui Conservation Reserve). Earth Sanctuaries in Australia is discussed at length. These studies lead to the strong conclusion that NGOs can produce conservation values viably, but their operations are frequently frustrated by government competition and bureaucracy.

Hartley argues that taxpayer subsidy of government conservation deters private investment in conservation services. He concludes that some form of private ownership, or at least private management, should be considered where government land is primarily used for tourism and recreation, has local volunteer groups dedicated to its conservation, is most suitable for multiple land use or is primarily of interest to Maori.

Nct conservation trades. Chapter 6 considers issues of multiple land use, sequential land use (such as mining followed by restoration), and offsets (where potential users of conservation land either purchase higher-value conservation land or provide finance that allows management to provide greater conservation outcomes from the area). Cases are cited of conservation groups unsuccessfully fighting for absolute conservation gains when compromise would have provided considerable benefits. Hartley concludes that the current situation in New Zealand where compensation for conservation activities on private land does not occur and where activities on the public conservation estate do not have to be justified in economic terms greatly reduces conservation outcomes everywhere.

The structure and performance of DoC. Quoting published evaluations of government reforms and the performance of DoC, Hartley stresses in Chapter 7 the inefficiencies of a department which, as one attendee of the launch of the book said, 'can act as both poacher and game keeper'. Furthermore, its multitude of functions - policy, advocacy, service provision, management of natural and historic resources - means that the provision of quality in one area often compromises quality in another. Arguing that conservation is predominantly a local issue, Hartley advocates a complete restructuring of DoC. Policy and advocacy should be split from service provision, and historic and natural resource management should be separated. Moreover, private conservation providers should be able to compete for government conservation funds. Reforms should focus on outcomes, including customer services, rather than functions, and so reflect the current internal structure of DoC (DoC, 1993).

All public conservation lands should be reclassified according to simpler and international criteria such as those of the International Union for the Conservation of Nature (IUCN). Moreover, there should be a capital charge on all public lands (returned to DoC) to encourage evaluation of alternative uses, and the sale of land with minimal conservation values. Suggestions for performance criteria and benchmarking are offered and compared with current reporting procedures. The 
suggested changes are supported with little detail, but are in accordance with government restructuring elsewhere.

Maori development and conservation. The long-term disadvantaged status of Maori is outlined in Chapter 8, and issues of welfare and anti-discrimination are discussed in an international context. Noting the failure of external assistance through welfare and anti-discrimination legislation, Hartley argues, in line with current government thinking, that an economic base under Maori control should be considered. A conservation estate could provide an opportunity to establish a network of Maori property rights and, in accordance with Maori calls (see for example Taiepa et al., 1997), a true Treaty of Waitangi partnership as required in law. Circumstances would determine whether management was undertaken solely by Maori or in partnership with other service providers (such as DoC, universities, or Crown Research Institutes). As Hartley (1997:460) concludes, 'outright Maori ownership of conservation assets - with appropriate regulation - represents a far more equal relationship than the set of (revocable) promises by the Department of Conservation to "do the right thing" by Maori concerns'. At the time of writing, a Maori group is camping on DoC-managed land at Lake Waikarimoana protesting against alleged inadequacies in conservation management. In view of the initiatives in comanagement with indigenous people undertaken in Australia and Canada, New Zealand clearly lags in this area.

Historic and cultural heritage. Hartley concludes that public ownership is not necessary for heritage preservation. Indeed, removal of the current disincentives for heritage protection would be part of a useful strategy.

\section{Reactions to the Book}

Reactions to the book were swift and largely predictable. In a press release issued on 18 December 1997, the Minister of Conservation 'rejected' the report, claiming it was 'based on greed and exploitation'. He claimed that 'charging for access ... would deprive thousands of New Zealanders of their birthright ... free public access is a core concept ... and is here to stay'. He announced that he would soon 'launch DoC's new business plan that would deliver more for conservation than the purist ideology of the Business Roundtable'. Additional comments about the privatisation of named locations and species (which are not mentioned in the book) and the subsequent release of the five-year plan suggest that the comment was ill-informed or meant to misinform.

DoC briefed its minister, its senior managers and interested stakeholder groups' on the contents of the book before its release. The brief (DoC, 1997b) contained the more contentious issues and took liberties in providing new and extreme examples. None of the rationale or justification for Hartley's recommendations was cited. Conservation groups, such as Forest \& Bird and Environmental \& Conservation Organisations, immediately went to press without reading the book, condemning suggestions such as entry fees and large fines for trespass, even though, 
as Roger Kerr (1998) points out, these same groups made no comment when DoC introduced large fines for using DoC huts without paying associated fees.

The ministerial brief further argues that the Resource Management Act and the Conservation Act are 'not resource allocation mechanisms' as claimed in the book, but are there 'to ensure that the land is managed appropriately in terms of the use to which it has been allocated, with appropriate public involvement, cost recovery, etc.'. Suggesting that income from cost recovery, determining where and how often pest control is implemented, the issues of whether visitor services are provided and which types, whether concessions are allowed, how money is distributed among parks, and other such decisions made by conservation managers are not about resource allocation confirms Hartley's thesis that current conservation policy-makers believe they stand outside normal economic decision-making.

The briefing claims that the discussion on 'intrinsic values' is irrelevant because DoC interprets these to mean 'existence values'. (Prior communication of this might have softened Hartley's criticism and helped others working in conservation.) It further argues that accountability is unrelated to the precise wording of the Conservation Act as there are numerous other documents that provide a more concrete basis for decision-making and accountability. It is true that many documents detail conservation management approaches. Yet neither of these claims withstands scrutiny. For example, if decision-making is related to 'existence values', then the current pest-control programmes suggest that the existence values of native ecosystems are of little consequence. With less than 25 per cent of native ecosystems being protected, currently or prospectively, from the three major herbivores, and less than 5 per cent with adequate predator control, existence values must be declining over most of the estate. Yet few would accept that the role of DoC is to manage the decline of the public conservation estate

The claim that accountability and decision processes are adequate must also be questioned in light of the December 1997 report of parliament's Transport and Environment Select Committee (New Zealand Parliament, 1997). This report was based on information from the Audit Office and the Parliamentary Commissioner for the Environment, both of which noted poor reporting of activities. The report records that the Audit Office noted that information-reporting systems were inadequate and that there was little evidence of self-review or peer review. The Commissioner for the Environment is recorded as saying that DoC's reports did not provide a clear picture of the department's achievements and gave very little sense of the actual results for conservation. Nor did annual reports 'set out the quality, effectiveness or relevance of the department's outputs'. Moreover, 'the annual report contained little precision about the methods by which the department assessed and monitored its activities and gave no clear sense of the medium and longer term directions for the department's contribution to conservation management in New Zealand' (New Zealand Parliament, 1997). It appears that the concerns raised earlier by Craig and Stewart (1994) have not been addressed.

The ministerial brief further dismisses the shift in emphasis that Hartley advocates from intrinsic value to public appreciation. The fact that few people 'enjoy' 
small and ugly invertebrates is used to argue that the existing approach is best. DoC's five-year business plan (DoC, 1998) offers a greater acknowledgment of the importance of peoples' values and provides some more specific reporting targets. However, it still lacks a clear focus, did not receive appropriate public input and retains imprecise wording (such as 'when appropriate') that allows management control always to override stakeholder challenges and retain an internal management focus. Moreover, the comment that the public does not appreciate invertebrates is countered by World Wildlife Fund's nature-trail initiative and the impending restoration of a private island.

Stephens and Lawless (forthcoming) argue that DoC's use of public values to influence funding allocations will result in the type of conservation that the public wants being subsidised by the types they do not. Moreover, they argue that as the public can already influence conservation outcomes through the political process, there is no need for a more rapid and direct approach of markets. This assumes that DoC managers have a superior understanding of conservation priorities, and that any public involvement should not influence the relative evaluations of DoC's priorities. If DoC believes that its brief is to safeguard conservation that is not appreciated by the public, then it should hand over conservation that the public does want to community and private management.

The current allocation of mammal control further illustrates these issues. On what criteria is 25 per cent of the public conservation estate chosen for possum and goat control? Saunders (1998:33) claims that the areas for full herbivore and predator control (mainland islands) are chosen in the light of 'scientific and management objectives'. That all these areas are remote from the large cities (although two are on tourist routes) suggests that a customer orientation or public access is certainly not a criterion: so much for 'the birthright of New Zealanders' in the lower socioeconomic groups that the Minister professes to care about in his press release.

DoC's rejection of multiple use and net conservation benefit are good examples of its outdated mentality. Multiple use before DoC was set up in 1987, and as practised in some US parks, meant that extractive or destructive uses sat together with non-extractive and passive use. Without a clear guideline of sustainability, the result was harmful to native ecosystems. For areas with high conservation value, such multiple uses pose major management challenges (see for example DoC, 1997c). With clearly articulated goals, it is possible to manage multiple-use mixes that have the potential to produce greatly enhanced conservation outcomes. For example, forest conservation areas are already managed for multiple uses such as wilderness recreation, erosion control, hunting, biodiversity conservation, and ecotourism. DoC could even heed Australian claims (Gottliebsen, 1998) that forests are carbon sinks that offset greenhouse gas-producing activities; in this way it could earn significant additional income for conservation. However, this would require management changes: a considerable part of the money would have to be used to control pests in order to reverse the current loss of carbon. Without control of both herbivorous and predatory mammals, the decline in native forest structure will result in a decline in carbon storage to a level below that achievable from rotation pine plan- 
tations. Moreover, failure to accept that conservation is part of the market or that such an additional non-extractive use is part of conservation business would mean that government will claim any carbon credits from the public conservation estate and allocate them to industry. If conservation wishes to stand apart from the rest of the economy by failing to advocate earnings from conservation assets, then the only remaining option is government welfare.

Does the defensive reaction from DoC and conservation NGOs partly reflect the past actions of business? The current state of New Zealand's biodiversity shows that much of the country's prosperity has been won at the expense of the environment (Glasby, 1991). Hartley (1997:217) argues that 'conservation needs to be better integrated with the rest of the economy' and that 'other economic activities can often be altered slightly to deliver significant conservation benefits'. He provides little argument other than suggesting 'incentives' and the need to reconsider property rights. A full analysis of conservation strategies for New Zealand would have included an economic evaluation and discussion of the role that business and councils play in conservation. Some multinational corporations (such as Interface Inc.) have shown that business can promote conservation by integrating environmental sustainability into their business plans through programmes such as The Natural Step (see for example Hawken 1993).

\section{Conclusion}

Internationally, conservation organisations have faced similar criticisms to those levelled at DoC, and dealt with them in different ways. For example, the US National Parks Service, worried about managing public lands but seemingly delivering few public goods, in 1991 produced the Vail Agenda, a set of recommendations for future management (United States Parks Service, 1991). Unlike with past reviews and restructuring of DoC, large numbers of people were involved, over half of them came from outside the US Parks Service itself, and it was independently chaired. The debate over how best to fund the parks continues (Leal \& Fretwell, 1997). The New South Wales National Parks Service has similarly announced a need to elaborate its vision for the next ten years through a public process. International agencies such as IUCN similarly argue for a need to re-evaluate conservation management and recommend economic approaches similar to those of Hartley.

New Zealand needs to undertake a similar project to establish a vision of conservation for New Zealand, preferably led by independent conservation professionals. The New Zealand government should commit itself to allowing the widest possible debate and to adopting the recommendations that are produced.

\section{References}

Costanza, R., R. d'Arge, R. de Groot, S. Farber, M. Grasso, B. Hannon, K. Limburg, S. Naeem, R. O'Neil, J. Paruelo, R. Raskin, P. Sutton \& M. van den Belt (1997), 'The Value of the World's Ecosystem Services and Natural Capital', Nature 387: 253-60.

Craig, J. \& A. Stewart (1994), 'Conservation: A Starfish Without a Central Disk?’, Pacific Conservation Biology 1: 163-8. 
Craig, J., C. Craig, B. Murphy \& A. Murphy (1995), 'Community Involvement for Effective Conservation: What Do the Community Want?', pp. 130-9 in D. Saunders, J. Craig \& E. Mittisky, Nature Conservation 4: The Role of Networks, Surrey Beatty, Chipping Norton.

Department of Conservation (DoC) (1992), Atawhai Ruamano Conservation 2000, Wellington.

- (1993), Greenprint: The Department and the Conservation Estate, Wellington.

(1997a), Conservation Action: Department of Conservation Achievements and Plans 1996/1997 $-1997 / 1998$, Wellington.

- (1997b), unpublished departmental briefing on report on Peter Hartley's Conservation Strategies for New Zealand, Wellington (18 December).

- (1997c), Issues and Options for Managing the Impacts of Deer on Native Forests and Other Ecosystems, Department of Conservation, Wellington.

- (1998), Restoring the Dawn Chorus: Department of Conservation Strategic Business Plan 19982002, Wellington.

Glasby, G. (1991), 'A Review of the Concept of Sustainable Management as Applied to New Zealand', Journal of the Royal Society of New Zealand 21: 61-81.

Gottliebsen, R. (1998), 'Comment: The Next Industrial Revolution', Business Review Weekly, Feb 9: $6-8$.

Hartley, P. (1997), Conservation Strategies for New Zealand, New Zealand Business Roundtable, Wellington.

Hawken, P. (1993), The Ecology of Commerce, Harper Collins, New York.

Kerr, R. (1998), 'Market Mechanisms and Conservation', paper delivered to a conference on Environmental Justice and Market Mechanisms, Faculty of Law, University of Auckland (March).

Leal, D. \& H. Fretwell (1997), Back to the Future to Save our Parks, PERC, Bozeman, MO.

Ministry for the Environment (MfE) (1997), The State of New Zealand's Environment, Wellington.

New Zealand Parliament (1997), Report of the Select Committee on Transport and the Environment report on DoC Estimates, Wellington (December).

Roberts, R. (1995), 'Biculturalism in Conservation in Aotearoa', pp. 132-40 in D. Saunders, J. Craig \& E. Mittisky, Nature Conservation 4: The Role of Networks, Surrey Beatty, Chipping Norton.

Saunders, A. (1998), 'Restoration Resume 3', Rare Bits 28: 32-3 (Department of Conservation, Wellington).

Stephens, T. \& P. Lawless (forthcoming), Cost-utility Evaluation of Natural Heritage Conservation Projects, Department of Conservation, Wellington.

Taiepa, T., P. Lyver, P. Horsley, J. Davis, M. Bragg \& H. Moller (1997), 'Co-management of New Zealand's Conservation Estate by Maori and Pakeha: A Review', Environmental Conservation 24: 236-50.

United States Parks Service (1991), National Parks for the 21st Century: The Vail Agenda, National Parks Service D-726.

I am grateful to Philip Cassey, Rod Hay, Roger Kerr, Neil Mitchell, Mere Roberts, Guy Salmon, Anne Stewart, Graham Ussher and two anonymous referees for comments on earlier drafts. 